\title{
APLICAÇÃO E ANÁLISE DE MAPA DE SERVIÇOS: UM ESTUDO DE CASO EM UMA PEQUENA EMPRESA DE SERVIÇOS AUTOMOTIVOS
}

\section{APLICATION AND ANALISYS OF SERVICES MAP: A CASE OF STUDY IN A SMAL COMPANY OF AUTOMOBILES SERVICES}

\author{
Edgard Monforte Merlo; ; Ieda Pelógia Martins²; Marcelo Seido Nagano ${ }^{3}$ \\ ${ }^{1}$ São Paulo University- FEA/USP - Ribeirão Preto - Brasil edgardmm@usp.br \\ ${ }^{2}$ Moura Lacerda University Center -CUML-Ribeirão Preto Brasil ieda.martins@bol.com.br \\ ${ }^{3}$ São Paulo University - EESC/USP - São Carlos - Brasil drnagano@usp.br
}

\begin{abstract}
Resumo
Este artigo analisa a aplicação do método de avaliação de processos/atividades conhecida como mapa de serviços para o setor de autopeças e serviços automotivos, foi utilizada a metodologia do estudo de caso com a finalidade de discutir esta técnica. A ferramenta analisada contribui ao analisar o processo em sua amplitude envolvendo o contato com o cliente que recebe o serviço prestado. Os resultados mostraram que o desenvolvimento do mapa de serviço requer a identificação de todas as atividades chaves, dos vínculos entre as atividades e da importância de cada um destes elementos para a qualidade global do serviço.
\end{abstract}

Palavras-chave: gestão de serviços; mapa de serviços; qualidade dos serviços essenciais; qualidade dos serviços complementares.

\section{Introdução}

A introdução dos automóveis populares no mercado brasileiro possibilitou a ampliação do mercado consumidor e também do mercado de serviços automotivos.

Devido ao crescente número de concorrentes neste mercado, é de fundamental importância que se tenha um diferencial que possa garantir a sobrevivência da empresa que atua nessa área. Conforme Homburg et al (2002) produto com serviços é uma das maiores formas que têm os varejistas de obter um diferencial atualmente. Por conseguinte, um diferencial de extrema importância e que ainda é pouco explorado, é o desenvolvimento de uma forma sistemática para administrar as operações a as atividades desenvolvidas pelos funcionários que estão em contato constante com seus clientes.

A partir dessa premissa, surge a questão de como identificar e administrar os serviços essenciais e complementares que irão compor uma vantagem competitiva em uma pequena empresa de autopeças. Na tentativa de responder a essa questão, o presente artigo tem como objetivo 
verificar, na prática, como se comporta a modelagem de mapa de serviço em uma pequena empresa de autopeças.

De acordo com Felisoni e Silveira (2001), o varejo brasileiro passou por significativas transformações desde meados da década de 1990, em razão do acirramento da concorrência trazida pela abertura da economia mundial, levando as organizações a se preocupar com a formação de preços, visto que a significativa redução da inflação alterou sensivelmente as condições de competição, a partir de 1994. Ao mesmo tempo, o movimento de defesa do consumidor consolidava que o consumidor era o elemento mais importante nos negócios das organizações. Desta forma, as empresas passaram a se preocupar mais com a concorrência, a empreender ações destinadas a cortar custos e a procurar criar valor para o consumidor, já que era possível realizar comparações efetivas de preços.

Consoante Santos e Costa (2002) podem-se observar nesse período uma reestruturação de empresas de vários segmentos varejistas, tendo por objetivo adequar organizações ao cenário competitivo. A disputa pelo consumidor, no período recente, levou muita dessas organizações a mudarem suas estratégias de negócios, uma vez que o consumidor se tornou mais exigente e informado, apresentando diferentes perfis e hábitos de consumo.

Conforme esses autores, as vantagens possíveis de serem obtidas pelos estabelecimentos varejistas parecem estar cada vez mais centradas na eficiência da estrutura de custos, na qualidade, no atendimento e nos serviços oferecidos do que no sortimento de produtos e preços, que já não podem ser considerados um marco diferencial. Isso implica na necessidade dessas empresas em focarem em ações voltadas à melhoria de serviços e do atendimento prestado, que podem significar muito para o consumidor em termos de percepção da qualidade e do valor atribuído à relação custo/benefício da compra. Essas ações variam desde medidas simples, como custos reduzidos, até serviços mais complexos e de maior custo. O novo cenário que surge nessa realidade abre espaço para uma economia mais moderna, dando ênfase ao oferecimento de valor para o consumidor em seus produtos e/ou serviços, de forma competitiva, reduzindo custos e gerando resultados.

A busca da satisfação dos desejos e necessidades dos clientes é o que deve orientar as estratégias da empresa para buscar a fidelização desse cliente. Entretanto, segundo Las Casas (2001), são poucas as empresas no Brasil que realmente aplicam uma orientação verdadeira para os clientes. Ainda conforme o autor, a prática daquela estratégia deve levar em consideração o aspecto humano e cultural para a satisfação dos consumidores. É necessária a implantação de uma filosofia empresarial de atendimento ao consumidor. Acima de tudo deve existir uma internalização da filosofia da empresa, ao invés de somente transmitir regras que não tem nenhum efeito prático, sem que os funcionários estejam convencidos de agradar os clientes. 
Tendo como objetivo a proposta apresentada este artigo esta estruturado apresentando inicialmente uma revisão bibliográfica sobre os conceitos utilizados de pequena empresa, administração de varejo, comportamento do consumidor e mapa de serviços. Finalizando, discorrese sobre o método da pesquisa e então, tem-se a apresentação do estudo de caso e as considerações finais do estudo.

\section{Referencial teórico}

\subsection{Pequena empresa}

Segundo Haberkorn (1999), pode-se definir uma empresa, independente de seu tamanho ou de sua área de atuação, como um conjunto de pessoas e recursos que geram uma receita vendendo seus produtos para um público determinado e que para garantir sua sobrevivência, a empresa necessita gerar uma receita maior do que as despesas gastas neste processo e o que sobrar, ou seja, o lucro, é distribuído aos proprietários da empresa.

O tamanho de uma empresa pode influenciar a sua administração. De acordo com Daft (2002), empresas de pequeno porte são melhores porque os requisitos essenciais para o sucesso de uma economia global são a capacidade de resposta e a flexibilidade nos mercados em rápida transformação.

Além do porte das organizações, o autor relata também a existência de mais um fator de grande importância que norteia os estudos sobre as organizações e que as separam em dois grandes blocos: organizações fabris e organizações de serviços. Como os nomes sugerem, as organizações fabris têm como objetivo principal a fabricação de produtos, enquanto as organizações de serviços atingem seus propósitos através de produção e fornecimento de serviços.

O que difere um serviço de um produto fabril é que o serviço, em geral, é um produto intangível que não existe até que seja requisitado pelo cliente e então um serviço não pode ser armazenado, estocado ou considerado como um bem acabado e se não for consumido imediatamente após a produção, ele desaparece. Isso normalmente pode significar que as empresas de serviço são de mão-de-obra e conhecimento intensivos, necessitando de muitos funcionários para atender as necessidades dos clientes, enquanto que as empresas de fabricação tendem a fazer uso intensivo do capital, recorrendo a tecnologias de produção em massa, processo contínuo e tecnologias avançadas de produção.

Geralmente, o cliente e o funcionário de uma empresa de serviços têm uma grande interação direta, o que não ocorre em empresas fabris. Essa grande interação direta significa que o elemento humano, aqui na figura dos funcionários, se torna muito importante nas empresas de serviço uma vez que o tratamento recebido desses funcionários afeta a percepção do serviço recebido e o nível de satisfação do cliente. Assim, observa-se que a qualidade de um serviço é percebida e não pode 
ser diretamente mensurada e comparada da mesma forma que acontece com a qualidade de um produto.

Segundo Goldstein (2003), em empresas prestadoras de serviços com alto contato com seus clientes, como é o caso da empresa objeto desse estudo, o gerenciamento do encontro do cliente com os funcionários da empresa constitui-se em um componente critico de estratégia de serviço e, para que esses encontros sejam satisfatórios, deve-se investir na qualidade de desenvolvimento dos empregados, incluindo sistemas de trabalho, treinamento e a atenção ao bem-estar do empregado, pois durante esses encontros, os funcionários precisam estar preparados para tomar decisões nãoprogramadas. Muitas empresas descobriram que quando seus empregados estão satisfeitos, os clientes ficam satisfeitos e os resultados financeiros melhoram.

Ao abordar o problema da estratégia empresarial, Porter (1989) a define como a busca de uma posição competitiva favorável perante a concorrência e que visa estabelecer uma posição lucrativa e sustentável contra as forças que determinam essa concorrência.

O tempo rápido de resposta também é outra característica que afeta a satisfação do cliente e a percepção do serviço de qualidade. Neste sentido, um serviço deve ser fornecido quando o cliente desejar e precisar dele.

Ao analisar uma empresa comercial de autopeças, observou-se que a mesma possui em sua operação características de grande intangibilidade (serviços oferecidos) associadas a produtos físicos (pneus, escapamentos entre outros itens) e que necessitam de um processo de integração eficiente para que ocorra um serviço prestado ao consumidor de qualidade diferenciada, gerando uma vantagem competitiva perante a concorrência.

Daft (2002) corrobora a questão acima ao relatar que na realidade, é difícil encontrar organizações com características totalmente prestadoras de serviços ou fabricação e que algumas empresas de serviços assumem traços de fabricantes e vice-versa. Assim, é comum encontrar organizações que podem pertencer ao setor de serviços, mesmo que o fornecimento de um produto seja uma parte significativa da transação. A maioria das organizações envolve alguma combinação entre produtos e serviços.

Outro aspecto a ser analisado é a atividade varejista que pode ajudar a fornecer mais elementos para compreensão das necessidades envolvidas neste segmento.

\subsection{Administração de varejo e serviços}

Segundo Parente (2000), varejo engloba todas as atividades relacionadas ao processo de venda de produtos e serviços que atendem a uma necessidade pessoal do consumidor final. $\mathrm{O}$ varejista é uma instituição cuja atividade principal consiste na venda de produtos e serviços para o consumidor final. 
Para um melhor entendimento, Parente (2000) conceitua os tipos de varejo, sua classificação e seus formatos, as instituições de varejo por tipo de propriedade e independentes. Assim, ele diz que um varejista independente tem apenas uma loja. São empresas pequenas, com administração familiar que, em geral, utilizam baixo nível de recursos tecnológicos. Os dois principais modelos de lojas de não-alimentos encontrados no Brasil são as lojas especializadas e as lojas de departamento. As lojas especializadas dominam o varejo de não-alimentos no Brasil. Concentram suas vendas em uma linha de produtos, tais como brinquedos, calçados, móveis, livros, confecções. Em geral, apresentam um sortimento profundo em algumas linhas de produtos e estão direcionadas para certo segmento de consumidores. Uma empresa comercial de autopeças pode ser considerada como fazendo parte deste segmento.

Uma das características dos varejistas de sucesso é a capacidade de entender adequadamente como o mercado funciona, e saber como atuar nesse mercado. Ao entender o funcionamento do mercado, o varejista sente maior facilidade para atuar e assim conseguir definir seus objetivos. Uma estratégia de varejo eficaz que, pode levar a uma vantagem competitiva, irá propor um programa de marketing que consiga satisfazer aos clientes de uma forma melhor do que qualquer concorrente, elaborado com base em uma completa análise de fatores externos e internos (KOTLER, 1999).

\subsection{Vantagem competitiva}

Segundo Porter (1998), uma vantagem competitiva surge do valor que a empresa consegue criar para seus clientes e que ultrapassa o custo de fabricação. Por valor entende-se aquilo que os clientes estão dispostos a pagar e valor superior como aquilo que provem da oferta de preços mais baixos do que os da concorrência por benefícios equivalentes ou do fornecimento de benefícios singulares que mais do que compensam um preço mais alto. Existem dois tipos básicos de vantagem competitiva (liderança de custo e diferenciação) que combinados com o escopo de atividades para quais uma empresa procura obtê-los levam a três estratégias genéricas: liderança de custo, diferenciação e enfoque. A estratégia tem duas variantes: enfoque no custo e enfoque na diferenciação. As duas primeiras estratégias buscam a vantagem competitiva em um limite amplo de segmentos, enquanto a estratégia do enfoque visa a uma vantagem de custo (enfoque no custo) ou uma diferenciação (enfoque na diferenciação) num segmento estreito.

Ainda conforme o autor, na liderança de custo, a empresa parte para tornar-se o produtor de baixo custo em seu segmento. Geralmente, essas empresas vendem um produto-padrão e dão ênfase considerável à obtenção de vantagens de custo absoluto e de escala em todas as fontes. $\mathrm{Na}$ estratégia genérica de diferenciação, a empresa procura ser única em seu segmento em algumas dimensões amplamente valorizadas pelos compradores. Os meios para a diferenciação são 
peculiares a cada indústria e podem ser baseados no próprio produto, no sistema de entrega e uma grande variedade de outros fatores.

A terceira estratégia genérica citada pelo autor é o enfoque e esta baseada na escolha de um ambiente competitivo estreito dentro de uma indústria. $\mathrm{O}$ enfocador selecionaria um segmento ou um grupo de segmentos na indústria e adaptaria sua estratégia para atendê-los, excluindo os outros. Essa estratégia tem duas variantes: no enfoque no custo, a empresa procura uma vantagem de custo em seu segmento-alvo, enquanto no enfoque na diferenciação a empresa busca a diferenciação em seu segmento-alvo.

A Análise de Cadeia de Valor é um modelo desenvolvido por Michael Porter para analisar de forma sistemática todas as atividades que uma empresa desempenha com o objetivo de identificar caminhos para melhorar o valor que a empresa oferece a seus clientes, por meio da redução dos custos e da ampliação dos benefícios (KOTLER, 1999).

O principio básico da cadeia de valores para Porter (1989) é que as atividades deveriam ser isoladas e separadas seguindo os seguintes critérios: se tivessem economias diferentes, se tiverem um alto impacto potencial de diferenciação, ou se representarem uma proporção significativa ou crescente de custo. $\mathrm{O}$ autor ainda reforça que a cadeia de valores não é uma coleção de atividades independentes, e sim um sistema de atividades interdependentes. As atividades de valor estão relacionadas por meio de elos dentro da cadeia de valores.

Em outro enfoque, a diferenciação e o posicionamento são ferramentas estratégicas de fundamental importância. De acordo com Parente (2000), a diferenciação consiste em desenvolver um conjunto de diferenças significativas que distingam um varejista de seus concorrentes, criando assim melhores condições para competir no mercado. O posicionamento é resultante de esforços de diferenciação e consiste em desenvolver características distintas em uma empresa varejista, para que ela possa ser percebida e ocupar uma posição marcante na mente dos consumidores. Esta estratégia geralmente é utilizada por empresas que detêm pequena parcela do mercado e que combinando estes dois elementos conseguem sobreviver e crescer em seus mercados de atuação.

A diferenciação, segundo Porter (1989) ainda permite que a empresa peça um preço-prêmio ou venda um volume maior do seu produto por determinado preço ou obtenha benefícios equivalentes, como uma maior lealdade do comprador durante quedas cíclicas ou sazonais. A empresa pode criar um valor que justifique o preço-prêmio reduzindo o custo ou elevando o desempenho, mas os clientes não pagam por valores que não percebam por mais reais que estes sejam. Mas a diferenciação não pode ser compreendida se a empresa for considerada como um todo, pois ela provém das atividades especificas que a empresa executa e do modo como afetam o cliente e, que também, geralmente ela é dispendiosa, pois, via de regra, a empresa precisa incorrer 
em custos para ser singular porque a singularidade exige que ela execute atividades de valor de uma forma melhor que a concorrência.

Corroborando com essas afirmações, Roth e Jackson (1995) citam que, devido ao fato dessas competências serem difíceis de serem adquiridas durante a rotina de transações de mercado e serem difíceis de serem copiadas, elas atraem novos clientes e servem também como proteção de mercado e colocam que capacidade competitiva pode ser definida como a habilidade que empresa como um todo possui de encontrar requerimentos de clientes que sejam altamente percebidos por eles. Como, por exemplo, personalização, preços, canais de distribuição e conveniência. Neste sentido que se insere a ferramenta do mapa de serviços ao possibilitar o atendimento personalizado e adequado em cada momento do serviço.

Porter (1989) ressalta que as empresas ainda confundem o conceito de qualidade com o de diferenciação. Embora a diferenciação envolva qualidade, ela constitui um conceito muito mais amplo. A qualidade normalmente esta associada ao produto físico. As estratégias de diferenciação procuram criar valor para o comprador por toda a cadeia de valores, englobando nitidamente os elementos associados ao serviço prestado.

Todos os aspectos acima mencionados mostram a importância da empresa agregar valor em toda a sua cadeia. Um dos aspectos fundamentais para essa estratégia é a diferenciação. Este artigo procurou evidenciar como através da análise detalhada do caso de uma empresa comercial de autopeças essa diferenciação pôde ser construída visando à satisfação do consumidor. Assim sendo, seria interessante analisar alguns aspectos do comportamento do consumidor de produtos e serviços no varejo.

\subsection{Comportamento do consumidor}

Um ponto de importância para a administração varejista está no entendimento de como se desenrola o processo decisório e o comportamento de compra dos consumidores. O conhecimento do comportamento do consumidor deve ser um tema prioritário entre varejistas, pois conseguir conquistar e satisfazer, compreendendo como ocorre o processo decisório e o comportamento de compra do consumidor é o propósito máximo de qualquer varejista (PARENTE, 2000).

Ainda conforme o autor, o propósito de qualquer empresa deve ser o de conquistar clientes e mantê-los com alto grau de satisfação. A razão de existir de uma empresa deve ser o de servir, atendendo e satisfazendo as necessidades de seus consumidores. A melhoria contínua das operações varejistas é um pré-requisito para a sobrevivência das empresas, já que o sucesso das empresas depende da satisfação dos seus clientes.

O produto ou o serviço objeto de venda oferece um conjunto de pistas, a estrutura física oferece mais pistas e os empregados - através de seus gestos, comentários, vestimentas, tom de voz 
- ainda mais pistas. Cada pista carrega uma mensagem, sugere algo para o cliente. A composição de todas as pistas gera a experiência total do cliente que sempre tem uma experiência - boa, ruim ou indiferente - sempre que ele compra um produto ou um serviço de uma empresa. A chave é como efetivamente a empresa gerencia essa experiência (BERRY et al, 2002).

Ainda conforme os autores supracitados, à medida que as expectativas dos clientes se elevam, a empresa varejista precisa superar seus concorrentes, para que a experiência de compra de consumidor seja superior à sua expectativa, e assim conseguir mantê-lo satisfeito e como cliente.

O setor comercial de autopeças poderia ser caracterizado como de compra comparada, pois se trata de produtos e serviços de alto valor agregado e com tempo considerável de durabilidade. Neste sentido, a criação de vantagem competitiva baseada em serviços oferecidos pode ser considerada de grande importância na escolha pelo consumidor.

A metodologia a seguir apresentada de mapa de serviços contribui para o desenvolvimento de um serviço diferenciado e que pode ser decisivo desde o reconhecimento do problema, passando pela decisão de compra e, principalmente, na avaliação pós-compra.

\subsection{Mapa de serviços}

Ruyter et al (1997) afirmam que a qualidade do serviço necessita ser tratada como um antecedente da satisfação nos serviços.

Conforme Lovelock et al (2004), as ofertas de serviços, em geral, consistem em um serviço essencial que se complementa com uma variedade de serviços complementares. O serviço essencial responde a necessidade do cliente de um serviço básico.

Ainda conforme o autor, o desenho de novos serviços constitui um desafio porque requer pensar em processos, pessoas e experiências, assim como em resultados e benefícios. Os processos que podem ser apresentados em tabelas que especificam as tarefas dos empregados e a seqüência operativa também descrevem a experiência do cliente em cada uma das etapas do serviço.

Entretanto, os serviços, por serem intangíveis e efêmeros, não constituem uma posse e sim uma experiência. Em alguns casos que existem elementos físicos que passam a pertencer ao cliente, uma parte significativa do preço corresponde ao valor agregado dos elementos de serviços complementares, que incluem mão-de-obra, experiência, utilização de equipamentos especializados (LOVELOCK et al, 2004).

A maioria das empresas de manufatura e serviços oferece aos seus clientes um pacote de benefícios, que incluem não somente a entrega do produto ou serviço essencial, mas também uma variedade de atividades adicionais. Cada vez mais, estes serviços complementares aportam a diferença entre as empresas de sucesso e as demais. O serviço essencial cedo ou tarde se converte em uma commoditie à medida que aumenta a concorrência e a indústria se torna mais madura. 
Os planejadores de serviços têm que incluir três componentes no desenho da oferta. $\mathrm{O}$ componente central é o serviço essencial, que responde as seguintes perguntas: em realidade, o que esta comprando o cliente? Qual é nosso negócio? O serviço essencial prove os benefícios centrais de resolução de problemas que buscam os clientes? (LOVELOCK et al, 2004).

O desenvolvimento de um mapa de serviço requer a identificação de todas as atividades chaves que a prestação e a produção de serviços e a especificação dos vínculos entre estas atividades (LOVELOCK et al, 2004).

Um aspecto central dos mapas de serviços consiste em distinguir entre as atividades que os clientes recebem e as atividades dos empregados e os processos de apoio, que os clientes não vêem. Entre ambos, existem alguns aspectos que se denominam linha de visibilidade. Segundo Fitzsimmons (2000), esta linha de visibilidade tem a função de separar as atividades do atendimento, onde os clientes podem obter evidências tangíveis do serviço, daquelas atividades consideradas de retaguarda, ou seja, que não são vistas pelo cliente. Para o autor, projetar um processo eficiente deve ser a meta para a retaguarda, reforçando que as suas operações têm efeito indireto nos clientes, com relação aos atrasos e erros.

Os mapas de serviços clarificam as interações entre os clientes e os empregados e o suporte necessário que aportam as atividades adicionais e os sistemas de controle. Dado que os mapas mostram as inter-relações entre os empregados, os processos operacionais, a tecnologia de informática e as interações com os clientes, facilitam a integração dos processos de direção, operações e recursos humanos dentro de uma companhia. Não existe uma única maneira obrigatória de preparar um mapa de serviço. Entretanto, se recomenda utilizar um enfoque consistente em toda a organização.

Deve-se, de acordo com Fitzsimmons (2000), fazer uma distinção entre os bens que pertencem aos clientes e aqueles que são fornecidos pela empresa prestadora de serviços. Ou seja, para serviços como lavanderia ou oficina mecânica, o serviço deve ser realizado sobre bens de propriedade do cliente; neste caso, recomenda-se assegurar a propriedade contra avarias ou perdas.

Além do mais, os mapas de serviços oferecem a oportunidade de identificar potenciais pontos de falhas no processo, que representam um risco de que as coisas saiam mal e diminua a qualidade do serviço. O conhecimento destes pontos de falha permite a gerencia desenhar procedimentos para evitar que ocorram ou preparar planos de contingência (ou ambos). Também pode-se detectar os pontos do processo onde os clientes têm que esperar, e então, desenvolver normas de execução para cada uma das atividades, que simulem tomada de tempo para as distintas tarefas, tempos de espera máximos entre as mesmas e anotações para marcar as pautas de interações entre os membros do pessoal e os clientes. 
Fitzsimmons (2000) discorre que a diferença entre as expectativas e as percepções dos clientes é dependente do tamanho e da direção das quatro falhas associadas à prestação do serviço. A primeira falha diz respeito à divergência entre as expectativas do cliente e a percepção, pela administração, destas expectativas. A segunda falha resultaria da incapacidade da administração em formular níveis de qualidade do serviço que corresponderiam às percepções das expectativas do cliente e da dificuldade para traduzi-la em especificações exeqüíveis. A terceira falha derivaria de problemas no desempenho do serviço, quando o serviço efetivamente prestado não atenderia às especificações estabelecidas pela administração. Uma falha na atenção direta ao cliente representa uma proporção maior nos encontros entre os clientes e a companhia de serviço. Portanto, adquire uma maior importância já que haverá menos oportunidades para criar uma impressão favorável.

O próximo subitem apresenta a metodologia utilizada na realização do estudo de caso da empresa prestadora de serviços automotivos.

\section{Método da pesquisa}

Para o desenvolvimento desse trabalho foi realizada uma pesquisa qualitativa com uma empresa brasileira, atuante no segmento automobilístico, que oferece produtos e serviços para automóveis.

Foi escolhido este método de pesquisa por oferecer como vantagem a riqueza dos detalhes obtidos. Por tratar-se de um tema atual no âmbito acadêmico, a pesquisa é de natureza exploratória, cujo objetivo consiste em definir melhor o problema, proporcionar as chamadas intuições de solução, descrever comportamentos de fenômenos, identificar procedimentos relevantes de ação ou obter dados adicionais antes que se possa desenvolver uma abordagem. A análise foi feita por meio da coleta de dados na empresa selecionada. Os dados foram analisados respeitando os objetivos definidos no início desse trabalho.

Utilizou-se, em um segundo momento, o estudo de caso para apresentação prática de uma empresa varejista de pequeno porte. Segundo Yin (2001) os estudos de caso são utilizados quando se colocam questões do tipo "como" e "por que", quando o pesquisador não tem muito controle sobre os eventos e quando o foco está concentrado em fenômenos contemporâneos inseridos em algum contexto da vida real.

De acordo com esse autor, como esforço de pesquisa, o estudo de caso contribui, de forma inigualável, para a compreensão que temos dos fenômenos individuais, organizacionais, sociais e políticos.

Dessa forma, para ele, a clara necessidade pelos estudos de caso surge do desejo de se compreender fenômenos sociais complexos, pois, o estudo de caso permite uma investigação para se preservar as características holísticas e significativas dos eventos da vida real, tais como ciclos de 
vida individuais, processos organizacionais e administrativos, mudanças ocorridas em regiões urbanas, relações internacionais e a maturação de alguns setores.

Yin (2001) ainda coloca o estudo de caso como uma estratégia de pesquisa eficaz porque na essência desse tipo de técnica de pesquisa a principal tendência em todos os tipos de estudo de caso, é que ela tenta esclarecer uma decisão ou um conjunto de decisões: o motivo pelo qual foram tomadas, como foram implementadas e com quais resultados.

\section{Estudo de caso}

Este artigo tem o objetivo de analisar como uma ferramenta de análise muito importante, o mapa de serviços, pode contribuir com a percepção da qualidade do serviço recebido pelo consumidor e servirá como elemento para a melhoria dos serviços prestados.

A contribuição do presente estudo é evidenciar como o mapa de serviços é uma ferramenta poderosa para a melhoria dos serviços prestados.

A empresa objeto de estudo é do setor de autopeças, oferecendo serviços como comercialização de pneus multimarcas, alinhamento, balanceamento computadorizado e óptico, limpeza de bicos, escapamentos entre outros. Pode ser considerada de pequeno porte, contando com cerca de dezessete funcionários e se constitui de duas lojas localizadas em locais de grande competição com diversas lojas oferecendo produtos e serviços similares, uma na cidade de Ribeirão-Preto e outra em Cravinhos, ambas no estado de São Paulo.

O serviço essencial oferecido pela empresa é o primeiro componente do desenho e os serviços complementares oferecidos são o segundo componente do desenho e também estão descritos logo abaixo.

A pesquisa foi realizada através de entrevistas com funcionários-chaves, da observação da realização dos procedimentos da empresa, de documentos e do sistema computadorizado utilizado pela empresa.

A seguir, será apresentado o modelo de mapa de serviços para identificar e analisar o serviço da empresa possibilitando o detalhamento desta e avaliação de melhora.

Quadro 1: Componentes do Mapa de Serviços

\begin{tabular}{|c|c|c|}
\hline & Objetivo & Empresa \\
\hline $1^{\circ}$ Componente & $\begin{array}{l}\text { Identificação do } \\
\text { serviço essencial }\end{array}$ & $\begin{array}{c}\text { Segurança em transporte através do oferecimento de peças e serviços de } \\
\text { automóveis com excelentes preços e qualidades. }\end{array}$ \\
\hline $2^{\circ} \mathrm{Co}$ & $\begin{array}{l}\text { Como se entrega } \\
\text { o serviço ao } \\
\text { cliente }\end{array}$ & $\begin{array}{c}\text { A empresa oferece várias opções de entrega do serviço prestado, como, } \\
\text { por exemplo: o cliente se dirige até a loja juntamente com seu carro e } \\
\text { aguarda o término do serviço. }\end{array}$ \\
\hline $3^{\circ} \mathrm{Cor}$ & $\begin{array}{l}\text { Serviços } \\
\text { complementares } \\
\text { oferecidos pela } \\
\text { empresa }\end{array}$ & $\begin{array}{l}\text { Dentre os diversos serviços destacam-se: garantia de peças e serviços; } \\
\text { esclarecimento de dúvidas quanto aos serviços e peças mais adequadas } \\
\text { para cada caso especifico; buscar e entregar veículos em lugar de maior } \\
\text { conveniência ao cliente; facilidades e opções de pagamentos; } \\
\text { profissionais qualificados e treinados; atendimento personalizado; sala }\end{array}$ \\
\hline
\end{tabular}




\begin{tabular}{|c|c|c|}
\hline $\mathbf{4}^{\mathbf{0}}$ Com ponente & $\begin{array}{c}\text { Seqüência de } \\
\text { prestação em } \\
\text { tempo }\end{array}$ & $\begin{array}{c}\text { de espera com confortáveis cadeiras e sofás, ar condicionado, televisão, } \\
\text { revistas, jornais, água, café, brinquedos infantis. }\end{array}$ \\
& $\begin{array}{c}\text { o vunto ao chega à loja e procede-se a análise dos serviços necessários. } \\
\text { necessário para a realização dos mesmos. Iniciam-se os procedimentos } \\
\text { técnicos. Terminado o trabalho, os funcionários de atendimento aos } \\
\text { clientes apresentam as opções de pagamento para que o cliente possa } \\
\text { escolher a que lhe for mais conveniente então, entrega-se a nota } \\
\text { fiscal, os termos de garantias e o veículo devidamente pronto. }\end{array}$ \\
\hline Pontos de falha & $\begin{array}{c}\text { Detectar os } \\
\text { pontos do } \\
\text { processo onde os } \\
\text { clientes têm que } \\
\text { esperar }\end{array}$ & $\begin{array}{c}\text { As esperas ocorrem quando faltam peças em estoque ou quando falta de } \\
\text { mão-de-obra especializada, ou ainda, quando faltam equipamentos. }\end{array}$ \\
\hline
\end{tabular}

Fonte: Pesquisa de campo (2008) 
Figura 1 - Primeiro Ato do Mapa de Serviços

Mapa de uma experiência em um Auto Center

Linha do tempo - PRIMEIRO ATO
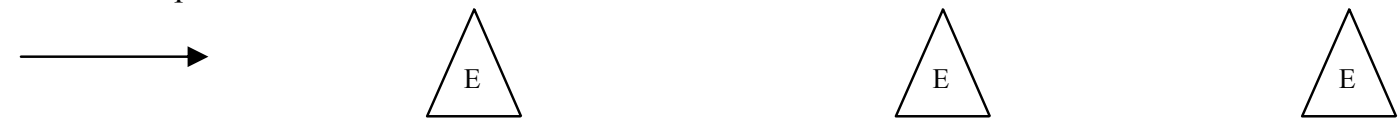

- Tempo de resposta Necessárias

Informações de disponibilidade de peças/serviços e preços

Evidência Física:

som e tom de voz cordialidade

Facilidade de acesso
Tempo

Opções de escolha Solução adequada

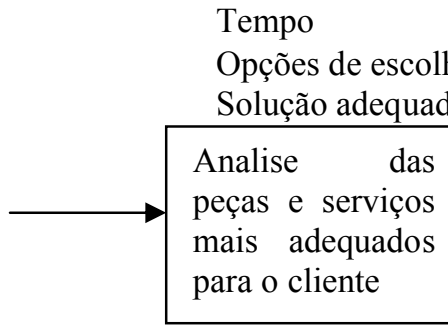

aspecto do empregado instalações físicas
Tempo

Disponibilidade

de mão-de-obra

Encaminhament o do veiculo para mecânico mais apropriado

aspecto do empregado organização da oficina tecnologia/ferramentas

Linha de Interação

\section{Pessoa de \\ Contato \\ (ação \\ visível)}

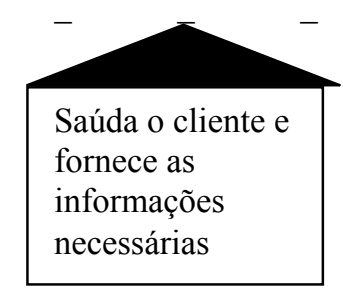

Linha de Visibilidade

Pessoa de contato

(ação invisível)
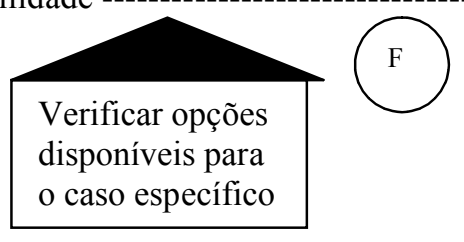

Analisar relação de custo/beneficio de cada opção
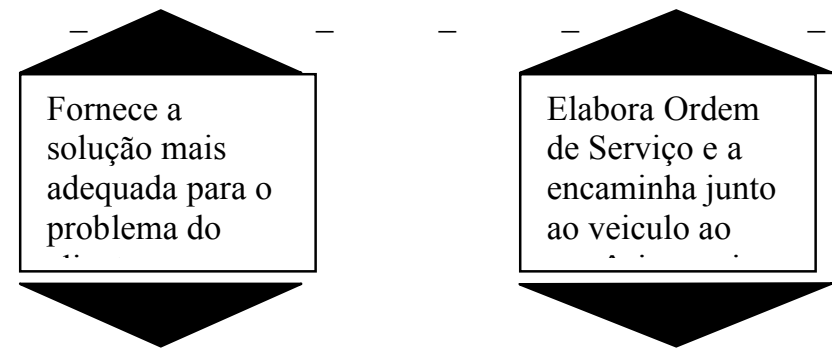

Linha de

Interação

Física

Interna

Processos

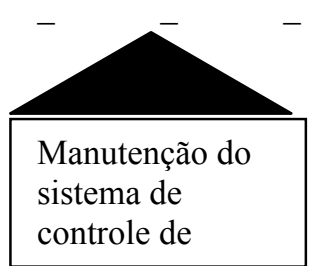

De suporte

Linha de interação De TI
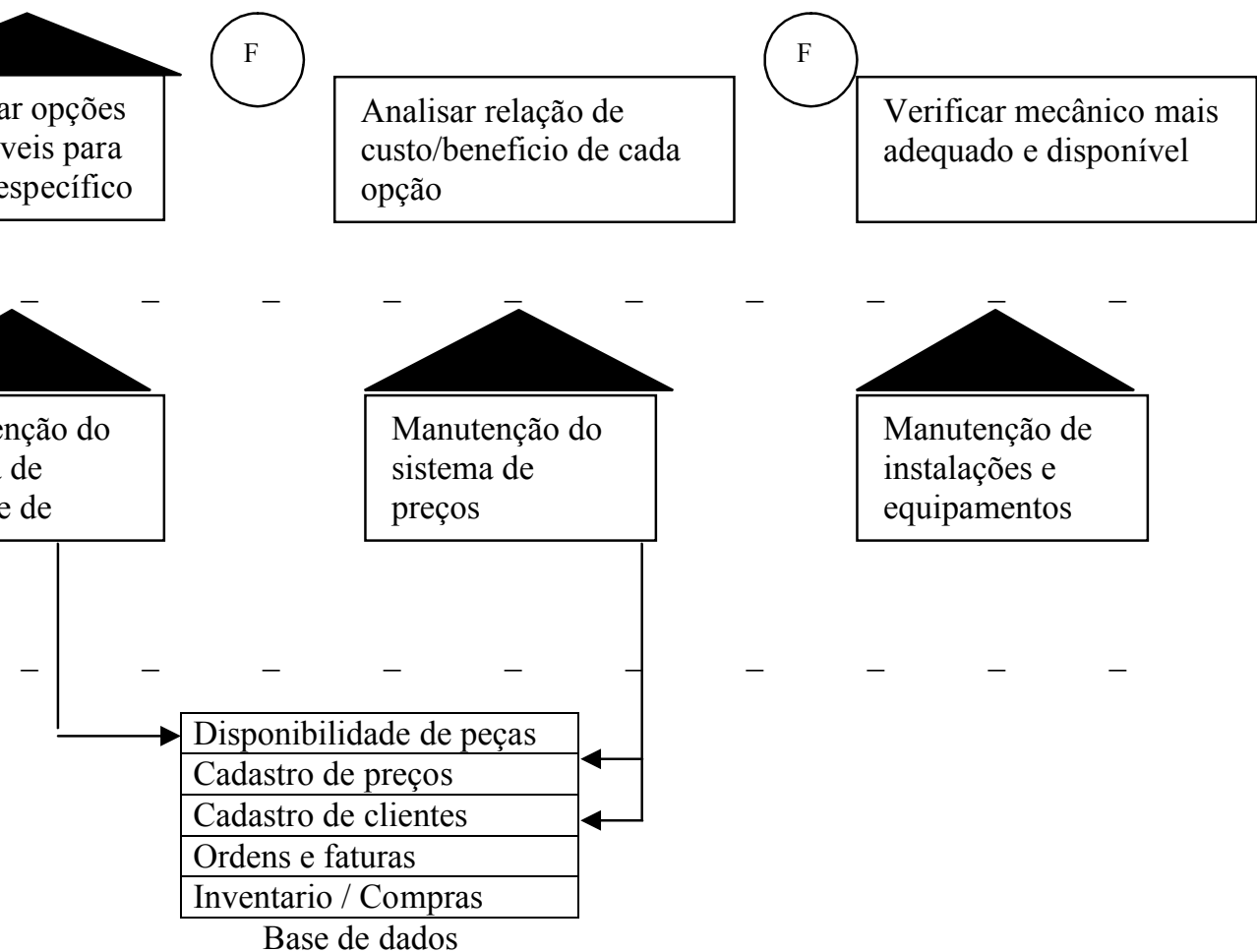

Fonte: Pesquisa de campo (2008) 


\section{SEGUNDO ATO}

Figura 2 - Segundo Ato do Mapa de Serviços
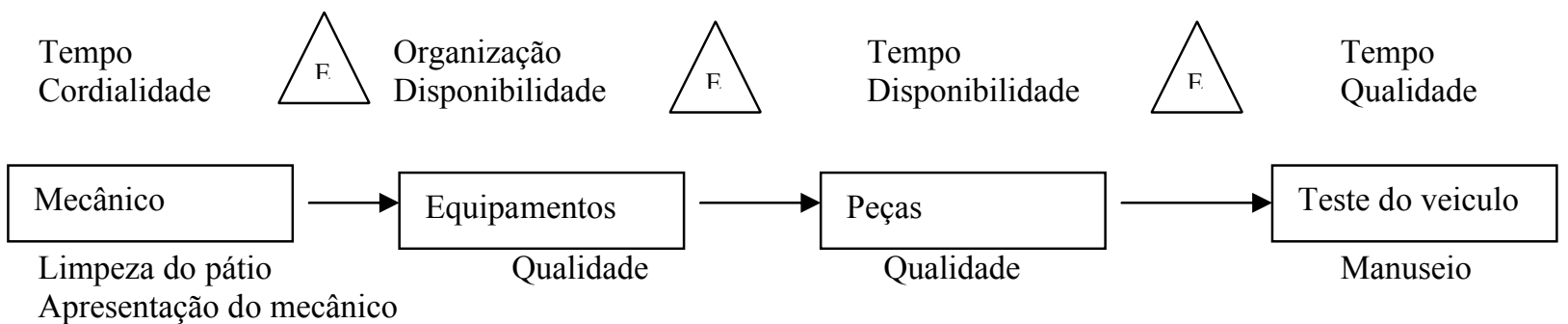

Apresentação do mecânico

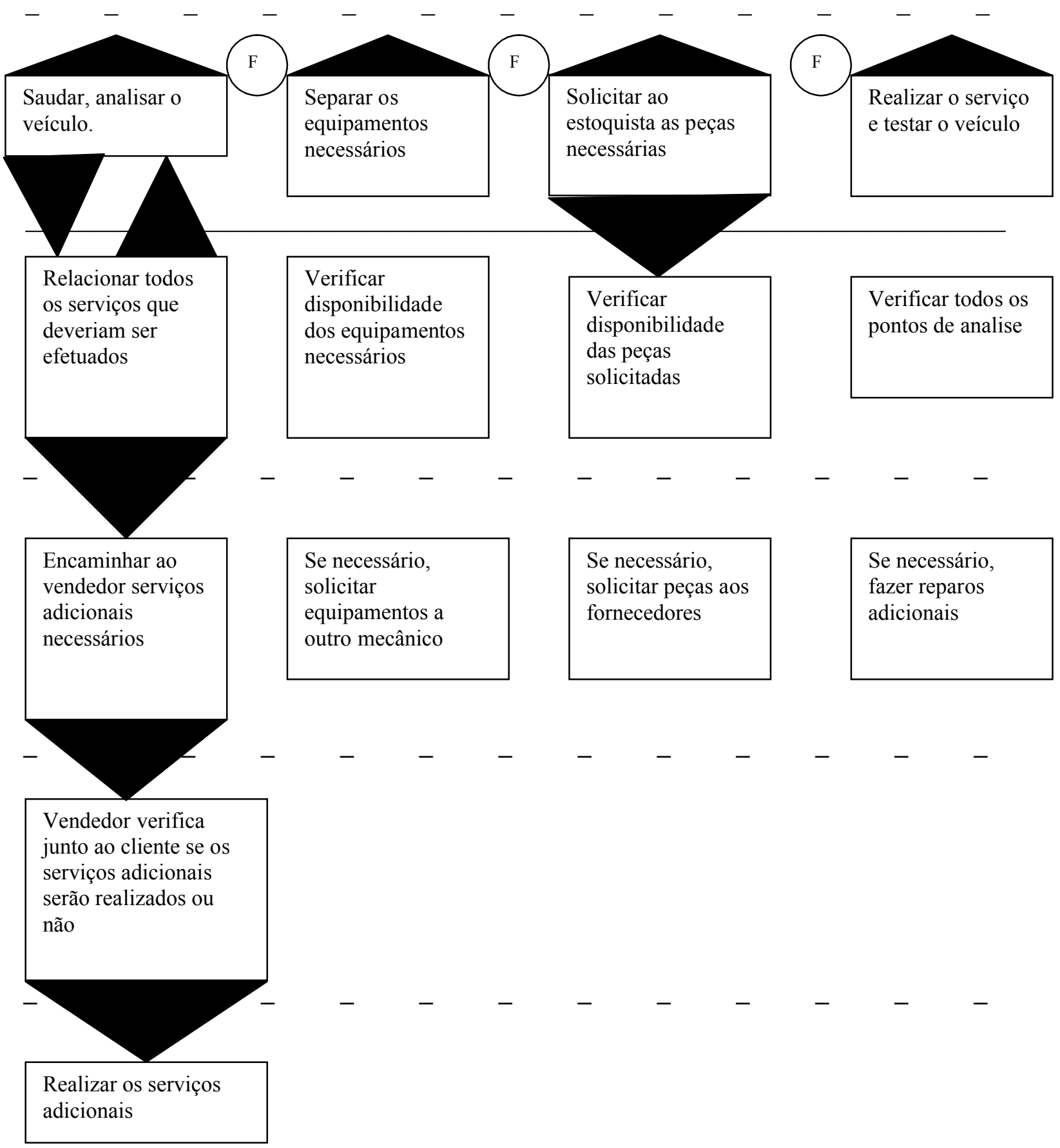

Fonte: Pesquisa de campo (2008) 
Tempo

Cordialidade

Evidência

Física

Linha de Interação Pessoa de contato (ação visível)

Linha de Interação Física Interna

Processo de suporte

Linha de Interação Interna de TI

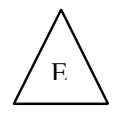

Manuseio do Veiculo

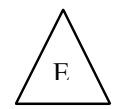

Tempo

Fatura correta e

Compreensível

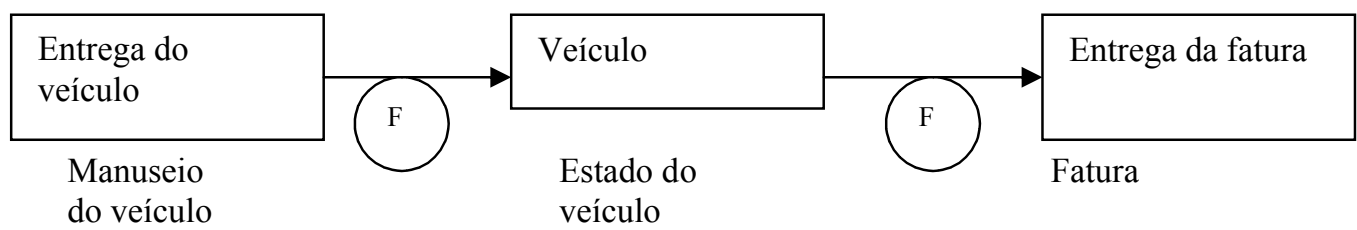

Levar veículo ate a saída da loja

\section{Constatar satisfação}

Verificar cadastro do cliente, levar fatura, receber o pagamento
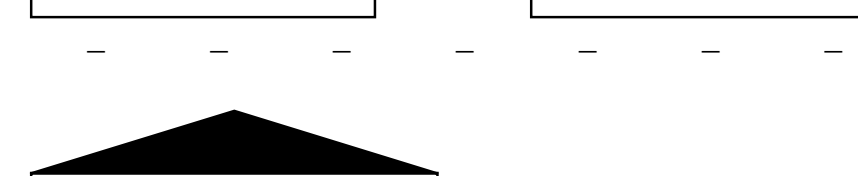

Manutenção das instalações da oficina

Preparação da fatura

Manutenção do Sistema de Faturamento

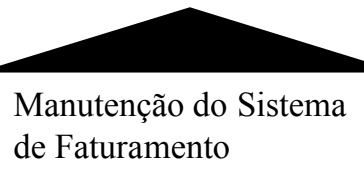

Compra / Entrega de peças
Estoque de pecas

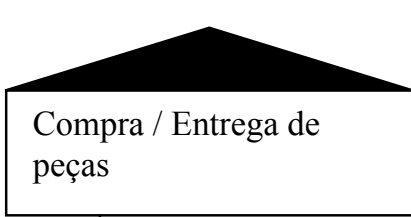

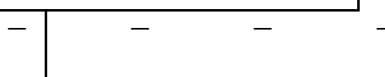

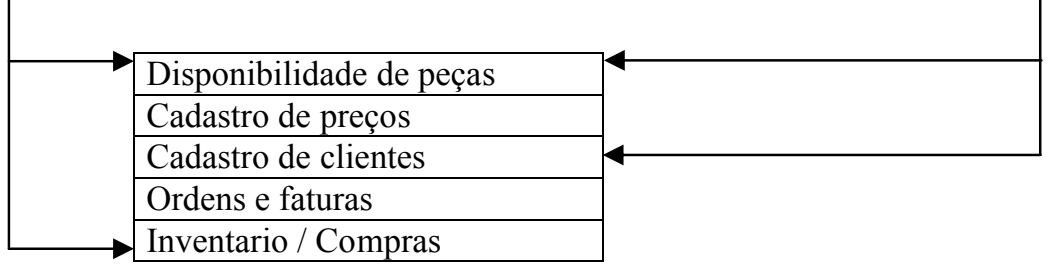

Base de Dados 

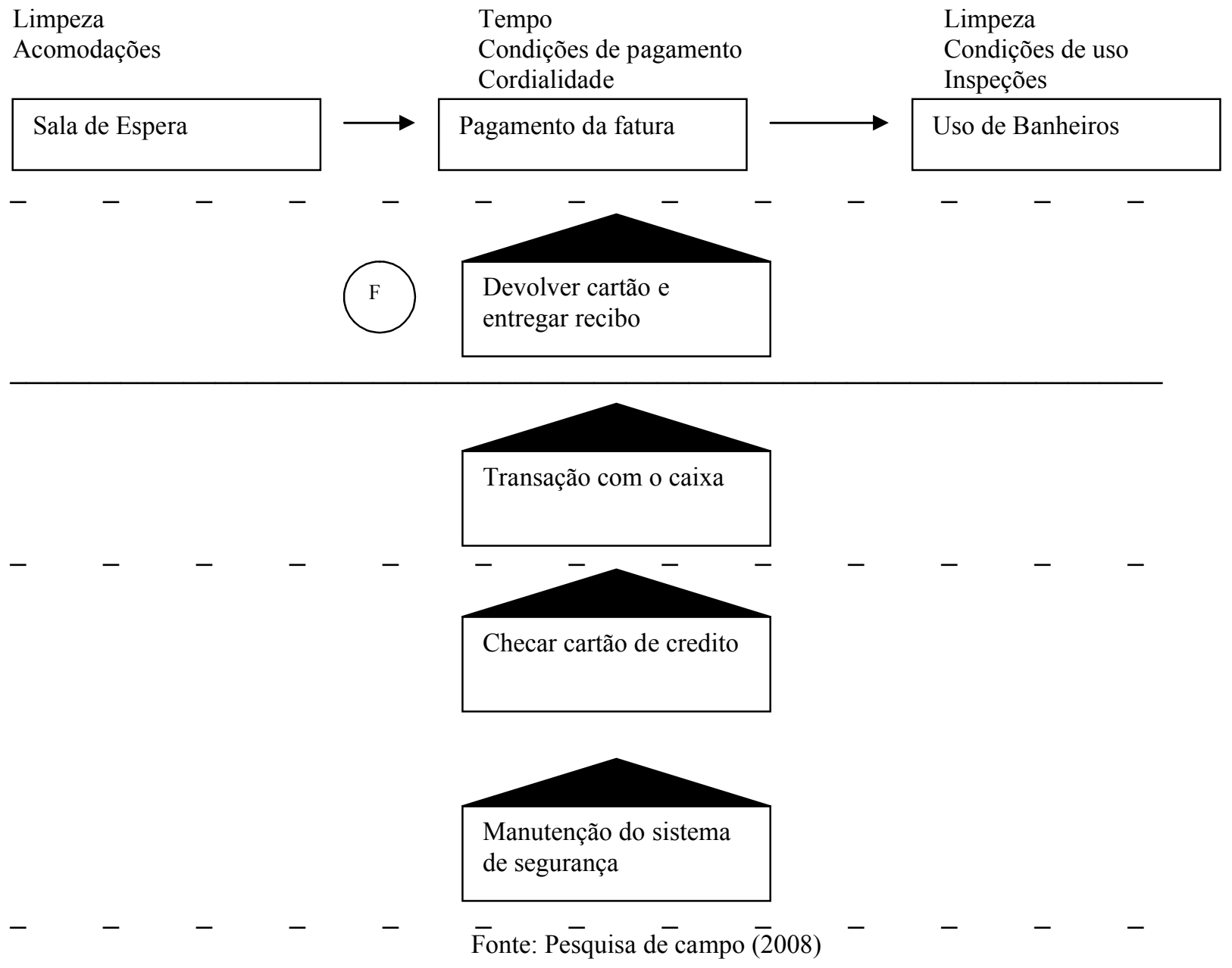

\section{Considerações Finais}

A maioria das empresas de serviços enfrenta uma concorrência ativa. Os executivos devem encontrar uma forma de criar vantagens competitivas significativas para seus serviços. Idealmente, deveriam apontar para segmentos que podem atender melhor que os outros provedores. $\mathrm{O}$ conceito de posicionamento é valioso porque obriga o reconhecimento explícito dos distintos atributos que compõem o conceito geral de serviço e acentuam a necessidade de compreender que atributos determinam o comportamento de seleção dos clientes. Neste sentido, os mapas de serviços apresentaram uma possibilidade de visualizar a informação reconhecida em estudos e de mostrar como se percebe o desempenho de diferentes empresas em relação aos atributos chaves. No presente estudo identificou-se uma dependência de estoques para o bom atendimento do serviço, este aspecto inclusive pode ser visto como essencial, sendo modificada sua gestão e possibilitando a criação de uma vantagem competitiva.

Por outro lado, a informação obtida combinada com a informação das preferências dos distintos segmentos, tais como nível de demanda que se pode antecipar em cada um dos elos, os 
mapas de serviços auxiliaram na indicação de oportunidades de criação de novos serviços ou de reposicionamento de serviços existentes. Neste sentido, a ferramenta possibilitou uma melhor compreensão dos diversos tempos de serviço e uma redução do tempo total, propiciando novamente um diferencial positivo junto aos clientes. Se considerar que oferecer tal serviço é compatível com os recursos e valores da organização, a companhia poderá desenvolver um nicho rentável no mercado.

A inovação é fundamental para uma direção de serviços efetiva, mas as inovações sustentáveis de serviços não são freqüentes. No caso da empresa em questão, o serviço essencial pode converter-se em um commoditie. A busca de vantagens competitivas está em concentrar-se em melhorias nos serviços complementares criadores de valores que rodeiam este serviço essencial.

A ferramenta de mapa de serviços se mostrou muito mais completa do que outras ferramentas mais conhecidas e utilizadas por identificar fatores importantes na prestação de serviços como serviços complementares, pontos de falha, pontos de espera e planos de contingência. Por outro lado, a complexidade da ferramenta pode dificultar sua utilização.

O caráter intangível dos serviços e das expectativas dos clientes em relação aos serviços prestados constituiu outra dificuldade apresentada pelo estudo em questão.

\begin{abstract}
This article analyzes the application of the evaluation process/activities method knew as services map to the auto parts and services automobiles. It was used the case study methodology to discuss this technique. The evaluated tool presents a contribution analyzing the process largely involving the contact with the consumer whose receive the service. The results showed that the development of services map need the identification of all the key activities, the relationship between activities and the importance of each one of these elements to the global quality of service.

Key-words: services management; services map; essentials services quality; complementary services quality.
\end{abstract}

\title{
Referências
}

BERRY, L.L.; CARBONE, L.P.; HAECKEL,S.H. Managing the total consumer experience. MITSloan Management Review, USA: p. 85-89, spring 2002, vol. 43, no. 3

BLACKWELL,R.; ENGEL J.F.; MINARDI,P. Comportamento do Consumidor. 9 ed. São Paulo: Thomson Pioneira, 2004.

CARSON, P.P.; CARSON, K.D.;KNOUSE, S.B.; ROE, C.W. Balance Theory applied to Service Quality: a focus on the organization, provider, and consumer triad. Journal of Business and Pshicology, University of Southwstern Louisiana, US: winter 1997, vol 12, nº 12, p. 99-120

CHIAVENATO, I. Introdução à teoria geral da administração. 7 ed. São Paulo: Makron Books, 2001.

CONSONI, F. Relatório Setorial Final, Setor: Automóveis. Disponível em: $<$ http://www.finep.gov.br/portaldpp/relatorio_setorial_final/relatorio_setorial_final_impressao.asp?lst_setor=9>. Acesso em: 27 outubro 2006. 
DAFT, R. L. Organizações: teorias e projetos. São Paulo: Pioneira Thomson Learning, 2002.

FELISONI, C.A.; SILVEIRA, J.A.G. Varejo competitivo. São Paulo: Atlas, 2001.

FITZSIMMONS, J. A.; FITZSIMMONS, M. Administração de serviços: operações, estratégia e tecnologia de informação. Tradução Gustavo Severo de Borba. Porto Alegre: Bookman, 2000.

GOLDSTEIN, S.M. Employee development: an examination of service strategy in a high-contact service environment. Production and Operations Management, New Orleans, USA: p. 186-203, ABI/INFORM Global, Summer 2003.

HOMBURG C., HAYER W.D., FASSNACHT M. Service Orientation of a retailer business strategic: dimensions, antecedents and performance outcome. Journal of Marketing. Chicago: p.86. Oct 2002.

KOTLER, P. Marketing para o século XXI: como criar, conquistar e dominar mercados. Tradução Bazán Tecnologia e Lingüística. São Paulo: Futura, 1999.

LAS CASAS, A.L. Novos rumos do marketing. São Paulo: Atlas, 2001.

LOVELOCK, C.; REYNOSO, J.; D’ANDREA, G.; HUETE, L. Administración de servicios: estrategias de marketing, operaciones y recursos humanos. México: Pearson Educación, 2004.

MASLOW, A. H. Introdução à psicologia do ser. Rio de janeiro: Livraria Eldorado Tijuca, 1970.

PAL, J.W.; BYROM, J.W. The five Ss of retail operations: a model and tool for improvement. International Journal of Retail \& Distribution Management, UK: p. 518-528, ABI/INFORM Global, 2003.

PARENTE, J. Varejo no Brasil: gestão e estratégia. São Paulo: Atlas, 2000.

PORTER, M. E. Vantagem competitiva: criando e sustentando um desempenho superior. Trad. Elizabeth Maria de Pinho Braga; rev. téc. Jorge A. Garcia Gomez. 12 ed. Rio de Janeiro: Campus, 1989.

REICHHELD, F.F. A estratégia da lealdade: a força invisível que sustenta crescimento, lucros e valor. Rio de Janeiro: Campos, 1996.

ROTH, A.V.; JACKSON, W.V. E III. Strategic Determinants of Service Quality and Performance: Evidence from the Banking Industry. Management Science, Evanston, IL: p. 1720-1733, ABI/INFORM Global, Nov 1995, 41, 11.

RUYTER, K.; BLOEMER, J.; PEETERS, P. Merging service quality and service satisfaction an empirical test of an integrative model. Journal of Economic Psychology 18, England: p. 387-406, Elsevier Science, 1997.

SANTOS, A.M.M.M.; COSTA, C.S. Características gerais do varejo no Brasil. Disponível em: $<$ http://www.bndes.gov.br/conhecimento/Bnset/varejo.pdf>. Acesso em: 01 junho 2002.

SANTOS, A.M.M.M.; PINHÃO, C.M.M. Área de Operações Industriais 2 - AO2 Gerência Setorial do Complexo Automotivo - $\quad$ Retrospectiva 98: Vendas. Disponível $<$ http://www.finame.gov.br/conhecimento/setorial/get2is22.pdf>. Acesso em: 27 outubro 2006.

SLEDGE, S. Does Porter's Diamond Hold in the Global Automative Industry? Advances in Competitiveness Research; USA: p. 22-32, ABI/INFORM Global, 2005.

TANABE, K.; WATANABE, C. Sources of small and medium entreprises excellent business performance in a service oriented economy. Journal of Services Research, India: vol 5, number 1 (April-September, 2005)

WERNER, J.R. e KUMAR V. Store-, market-, and consumer-characteristics: the drivers of store performance. Marketing Letter. Netherland, p. 5-22, Kluwer Academic Pub, 1999.

YIN, R. K. Estudo de caso: planejamento e métodos. 2 ed. Porto Alegre: Bookman, 2001.

Inserir aqui dados completos de TODOS os autores: 
Nome completo: Edgard Monforte Merlo

Filiação institucional: FEARP/USP

Departamento: Economia e Administração de Empresas

Função ou cargo ocupado: Professor Doutor

Endereço completo para correspondência (bairro, cidade, estado, país e CEP): Av. Bandeirantes, 3900 - Ribeirão Preto - SP - Brasil - Cep 14040-900

Telefones para contato: 1636023901

e-mail: edgardmm@usp.br

Nome completo: Ieda Pelógia Martins

Filiação institucional: Centro Universitário Moura Lacerda

Departamento: Faculdade de Administração de Empresas

Função ou cargo ocupado: Professora

Endereço completo para correspondência (bairro, cidade, estado, país e CEP): Av Caramuru, 2200 apto 433 Republica - Ribeirão Preto - SP - Brasil - Cep 14030-000

Telefones para contato: 1636212363

e-mail: Ieda.Martins@bol.com.br

Nome completo: Marcelo Seido Nagano

Filiação institucional: EESC/USP

Departamento: Escola de Engenharia

Função ou cargo ocupado: Professor Doutor

Endereço completo para correspondência (bairro, cidade, estado, país e CEP): Av Trabalhador Saocarlense, 400 - São Carlos - SP - Brasil - Cep 13566-590

Telefones para contato: 1633739428

e-mail: drnagano@usp.br 